\title{
Alta Floresta: uma colônia de Ariosto da Riva em Mato Grosso
}

\section{Alta Floresta: an Ariosto da Riva's colony in Mato Grosso}

Armando Wilson Tafner Junior - Professor do Departamento de Economia da Universidade Federal de Mato Grosso (UFMT). Economista pela Universidade Estadual em Maringá (UEM). Mestre e Doutor pelo Núcleo de Altos Estudos Amazônicos/UFPA. E-mail: armandowilson@hotmail.com

Fábio Carlos da Silva - Doutor em História Econômica pela Universidade de São Paulo/ USP. Professor do Núcleo de Altos Estudos Amazônicos, da Universidade Federal do Pará.E-mail: fcsilva.ufpa@gmail.com

\section{Resumo \\ Ariosto da Riva, devido à fundação de diversas cidades no Oeste e no Norte do Brasil, ficou conhecido como o último bandeirante. Assim como os verdadeiros bandeirantes, Ariosto da Riva foi sempre adjetivado de forma contraditória, como símbolo de bondade para uns e de perversidade para outros. Neste trabalho, é evidenciada a forma de colonização imposta pela INDECO, empresa de propriedade de Ariosto da Riva, na cidade de Alta Floresta, na Amazônia mato- grossense, demonstrando os aspectos históricos e sociais resultantes de tal processo de colonização.}

\begin{abstract}
Ariosto da Riva, because the foundation of various cities in the west and north of the Brazil, stayed known as the bandeirante ultimate. With the real bandeirantes, Ariosto da Riva was always adjective at so contradictory, as goodness symbol for some and evil for others. In this paper, it is shown how to colonization imposed by INDECO, Ariosto company of the Ariosto da Riva propriety, in the city of Alta Floresta in Mato Grosso Amazon, demonstrating the historical and social aspects resulting from this process of colonization.
\end{abstract}

\section{Palavras-chave}

Colonização. Amazônia. Conflito Social. Expansão da Fronteira Agropecuária

\section{Keywords}

Colonization; Amazon; Social Conflict; Expansion of the Agricultural Frontier. 


\section{INTRODUÇÃO}

Ariosto da Riva nasceu em Agudos, interior de São Paulo, em 25 de novembro de 1915. Era filho de pais italianos, Ludovico da Riva e Vitória Furlani da Riva. Seu pai era maestro e professor de música, e sua mãe dedicava-se totalmente aos trabalhos domésticos. Viveu com os pais até os 16 anos de idade, quando saiu para tentar a vida nos garimpos de diamantes. Seu primeiro destino foi a região serrana do Espírito Santo, no município de Santa Teresa. De lá foi para Serra do Sincorá na Bahia, na Chapada Diamantina. Buscando diamantes, Ariosto foi para Diamantina, Minas Gerais.

Sempre atrás da maior gema ${ }^{1}$ de diamante possível, foi para o rio Maú, na Amazônia, divisa entre o estado de Roraima, a Guiana e a Venezuela. Nessa região conseguiu acumular capital por meio das pedras preciosas e adquiriu uma porção de terra em Diamantina e voltou para Minas Gerais. Em Diamantina, casou-se com a professora Helena e lá nasceram seus quatro filhos: Ludovico, Vitória, Marília e Vicente. No mesmo município, continuou a garimpar diamantes, chegando a desviar o leito do rio Jequitinhonha para a sua propriedade. Após buscar diamantes em toda a sua mocidade, montou uma lapidadora de pedras preciosas e semipreciosas em Belo Horizonte.

Com os ganhos de capital melhorando e a acumulação acontecendo, Ariosto da Riva adquiriu uma pequena propriedade de 15 hectares em Marília, interior de São Paulo, que possuía cerca de mil pés de café. Esta propriedade era vizinha de uma plantação pertencente a Geremia Lunardelli, o rei do café. Ariosto passou a prestar serviços para a fazenda vizinha e acabou por conhecer pessoalmente e trabalhar para Lunardelli (FOLHA DA FLORESTA, 1989). O rei do café estava diversificando os seus negócios no Norte do Paraná, loteando uma gleba de sua fazenda, que tinha sido atingida pela geada e que foi denominada Lunardelli por Ariosto da Riva. A ideia era colonizar a região vendendo os lotes de terrenos para os trabalhadores de café. Ariosto da Riva foi seu homem de confiança para esta empreitada. A colonização teve como publico alvo os trabalhadores de várias fazendas que viviam no regime de colonato. Como comandante do processo, Ariosto teve acesso aos números de assentados e as cifras que Lunardelli atingiu quando resolveu executar a colonização no Centro-Norte do Paraná.

Com Lunardelli, Ariosto aprendeu a colonizar e vislumbrou a oportunidade de ser o colonizador e fundou sua própria empresa, a Colonizadora Vera Cruz Ltda, em 1952, após o governo de Getúlio Vargas distribuir 300 mil hectares na Colônia Agrícola Nacional de Dourados. Ariosto adquiriu parte dessas terras

1 Nome popularmente conhecido entre os garimpeiros dado à pedra de um mineral lapidado. 
que eram margeadas pelo Rio Amambaí, e lá começou o seu $1^{\circ}$ empreendimento colonizador, e que mais tarde viria ser a atual cidade de Naviraí, no Mato Grosso do Sul.

A primeira atividade econômica na cidade foi madeireira, devido à abundância desse recurso natural. Já em 1953 o desmatamento acabou gerando conflitos com os silvícolas que habitavam a região. Estimava-se cerca de 44 tribos indígenas instaladas na região colonizada por Ariosto da Riva.

Os conflitos sociais acompanharam os empreendimentos de Ariosto da Riva que visavam à colonização. Este trabalho trata do processo de colonização privada no Norte de Mato Grosso e do desenvolvimento do município de Alta Floresta, implementado por Ariosto por meio da sua empresa de colonização, a Integração, Desenvolvimento e Colonização (INDECO).

\section{PRIVATIZAÇÃo DA TERRA NA AMAZÔNIA MATO-GROSSENSE}

Ariosto da Riva que já havia iniciado uma colonização em Naviraí (MS), na fronteira com o estado do Paraná, por meio de sua empresa Colonizadora Vera Cruz Ltda., entre os anos de 1952 e 1963, e posteriormente destinou suas atenções ao Norte mato-grossense, adquiriu 400 mil hectares nesta região, que antes da aquisição do colonizador, seriam destinados a um projeto científico integralmente dedicado à Amazônia. O projeto Aripuanã, consistia em criar a Cidade Científica de Humboldt. Caberia a essa universidade, chamada na época de Uniselva, realizar o levantamento de capital natural na região, apontando alternativas não predatórias e o aproveitamento racional das potencialidades oferecidas pelo bioma amazônico. A pesquisa seria o instrumento para o desenvolvimento da região e a preservação de ecossistema. Até mesmo as novas infra-estruturas teriam que se enquadrar aos novos conceitos estabelecidos na região para evitar danos sociais, econômicos e a destruição inútil das reservas naturais. Ideias atuais que foram pensadas a mais de quarenta anos atrás. Ideia que não conseguiu sair do imaginário. Os 2 milhões de hectares onde seria construída a cidade científica foram "leiloados" e dentro dessa área estavam os 400 mil hectares adquiridos por Ariosto da Riva.

E o grande objetivo do projeto Aripuanã, que era o de promover a integração da Amazônia de forma científica e racional, diametralmente oposta à da Transamazônica e a filosofia de abrir estradas, parece que não terá seguimento. Tal como ocorreu com o Projeto Alto Turi, elaborado pela Sudene em 1962, Humboldt foi finalmente vencido pelos seus maiores inimigos: os interesses estrangeiros pelas jazidas minerais amazônicas, e os grandes grupos econômicos nacionais e estrangeiros (abençoados 
pelo ex governador de Mato Grosso) [José Fragelli] interessados na industrialização da madeira e na substituição das florestas por imensas pastagens (JORNAL OPINIÃO, 1975, p. 6).

Com o poder econômico concentrado no Centro-Sul, assim como as grandes empresas, o projeto Aripuanã foi desfeito e suas terras cedidas à CODEMAT em 1973. Era o maior estoque de terras devolutas do Estado e que foi destinado a projetos de colonização, exploração agroindustrial e agropecuária, industrialização de celulose, mineração e cooperativas mistas de produção e consumo, para quatro empresas que conseguiram esse direito em um processo licitatório.

Quadro 1 - Resultado do Leilão de Aripuanã

\begin{tabular}{|l|r|}
\hline \multicolumn{1}{|c|}{ Empresa } & \multicolumn{1}{c|}{ Área (ha) } \\
\hline Rendanyl S. A. & 1.000 .000 \\
\hline INDECO S. A. & 400.000 \\
\hline Colniza S. A. & 400.000 \\
\hline Juruema Empreendimentos S/C Ltda. & 200.000 \\
\hline
\end{tabular}

Fonte: Huertas (2009)

Em 5 de outubro de 1973 Ariosto da Riva assinou a escritura dos 400 mil hectares adquiridos e que deram origem aos municípios de Alta Floresta, Paranaíta e Apiacás.

\section{O INÍCIO DA COLONIZAÇÃO DE ALTA FLORESTA}

A expansão da fronteira agropecuária para o Mato Grosso foi resultado de política de colonização promovida pelo governo federal que pretendia explorar e absorver a mão-de-obra familiar excedente, alocando-a nas zonas de fronteira, que eram entendidas como "vazios demográficos".

Com a intenção de evitar e amenizar conflitos pela terra em regiões onde a necessidade de mão-de-obra diminuiu, significativamente, foram criados novos espaços para onde os colonos foram direcionados, cessando os problemas fundiários e as tensões sociais na terra de origem desses migrantes.

Assim surgiu a possibilidade da colonização privada promover a formação do espaço na Amazônia. Era o início da construção do município de Alta Floresta, que posteriormente foi tratado como um modelo de colonização, e passou a fazer parte dos discursos políticos, aparecendo em diversos veículos de comunicação. Não era mais uma tentativa de ocupação da Amazônia, mas sim um projeto organizado, com todas as chances de ser um sucesso como não havia ocorrido até então. 
A jornalista americana Ellen Bronfield Gelde esteve no seminário mencionado e foi a Alta Floresta fazer uma matéria e publicou no jornal O Estado de São Paulo e no New York Times, que:

[...] ela havia descoberto em meio a selva amazônica um outro Brasil em que há todos os tipos de oportunidades para quem deseja trabalhar, todos os tipos de desafios para quem tem coragem. Um Brasil que, talvez seja o melhor lugar do mundo para a juventude viver (ROSA, 1999, p. 21).

Alta Floresta tomou grandes proporções em seus primeiros anos que foram alicerçados nas políticas incentivadoras de colonização e da expansão da fronteira agropecuária para o Oeste, que buscava integrar as regiões menos ocupadas aos grandes centros urbanos. A SUDAM, a Superintendência de Desenvolvimento do Centro-Oeste (SUDECO), o Banco da Amazônia (BASA) e o Banco do Brasil (BB) ficaram encarregados de organizar a ocupação. Uma de suas obras foi a BR-163 ou Cuiabá-Santarém, que para sua abertura teve duas frentes de trabalho formadas por integrantes do 9ํㅡㄹ Batalhão de Engenharia e Construção do Exército Brasileiro (9ํㅡㄹ), que estava lotado no Rio Grande do Sul, e foi reinstalado em Cuiabá. A primeira começou a abrir a estrada em direção à serra do Cachimbo. A segunda abria a estrada de Santarém em direção ao Mato Grosso. Avançavam em média $5 \mathrm{~km}$ por dia e o encontro se deu no Sul do Pará em 1976 depois de 5 anos de trabalho (ARAÚJO, 1999).

A BR-163 ficou conhecida como a estrada dos colonos, pois foi construída para facilitar a chegada dos colonos que, em sua maioria, vinham da região Sul, mais especificamente da região Norte do Paraná. Dois grandes projetos foram instalados à margem da BR-163: Sinop e Colíder. A gleba INDECO que posteriormente viria a ser Alta Floresta, estava a $207 \mathrm{~km}$ da BR-163. Esta gleba tinha o mesmo nome da empresa compradora da área e que foi responsável por sua ocupação. A Integração, Desenvolvimento e Colonização (INDECO), de propriedade de Ariosto da Riva, foi criada para promover a colonização no Norte de Mato Grosso. Primeiramente em Alta Floresta e posteriormente em Apiacás e Paranaíta. Foi por meio da INDECO que Ariosto começou as obras de infraestrutura de Alta Floresta, dando início ao processo de colonização da área.

Proprietário do cartório Dalla Riva, o 1 cartório de Alta Floresta, o sr. Mário César Dalla Riva era sargento do Exército e foi para Cuiabá transferido do Rio Grande do Sul, junto com o 9o BEC, que estava encarregado de construir a BR-163. E quando questionado sobre como conheceu Ariosto da Riva, respondeu: 
Por motivos religiosos eu frequentei a casa do Coronel José Meirelles, que foi prefeito, cuiabano e era o comandante do 9 Batalhão. Ele frequentava minha casa, eu frequentava a casa dele [...] e quando acabei meu curso de direito ele me disse para ir para Alta Floresta trabalhar com a INDECO. Eu já tinha 20 anos de serviço e ele me falou o seguinte "Você tira sua licença de 6 meses e fica responsável pela construção da estrada [MT-208]. Se te agradar você fica trabalhando lá se não te agradar você volta” Dito e feito! Vim pra cá. Fiquei com uma função burocrática no financeiro da INDECO, cuidando da folha de pagamento e acabei ficando e dei baixa no exército. [Em que ano o Sr. deu baixa no exército?] Foi em 1975 (DALLA RIVA, 2013, não paginado).

$\mathrm{Na}$ fala de César Mário Dalla Riva, vê-se uma forte ligação de Ariosto da Riva com os militares. O coronel José Meirelles enviou um sargento para trabalhar na INDECO por 6 meses já aceitando a sua liberação e a saída do exército. Certamente que a construção da MT-208, estrada que liga a BR-163 a Alta Floresta, já estava nos planos da ditadura militar em 1976, pois Dalla Riva foi enviado para lá em 1975. A construção da estrada foi finalizada em 1981.

Nesse período referente à década de 1970, cada vez mais os projetos de colonização do INCRA não atingiam seus objetivos. Além da falta de condições mínimas de subsistência, a forma de ocupação era feita em relação ao cultivo de terras.

Tanto no passado como no presente, sempre foi reduzida a porcentagem das terras exploradas na Amazônia. A economia principalmente extrativista, a escassa agricultura e a pecuária rústica e extensiva, sempre ocuparam apenas uma parte pequena das terras existentes e aproveitáveis. $\mathrm{Na}$ década dos setenta ainda era marcante o caráter extrativista do conjunto da economia da região. A estrutura agrária da Amazônia é denominada por certas constantes histórias de extroversão, mercantilismo predatório e monopólio que marcam suas principais características. O extrativismo como forma predominante de economia deu a tônica a essa sociedade agrária reforçando ainda os condicionamentos geográficos. Essa economia de coleta e de exploração crua de recursos naturais marginalizou a agricultura gerando instabilidade generalizada da sociedade agrária amazônica e a dispersão dos núcleos de povoamento da região. Daí porque sempre foi reduzida a exploração agrícola e pecuária das terras. Muitas terras serviram no passado e continuam a servir no presente como terras de árvores, animais, aves e minerais, para a coleta, consumo ou comércio. Ao mesmo tempo persistem sítios e latifúndios ao lado de empresas agrícolas (IANNI, 1981, p. 92).

Os novos colonos traziam o conhecimento tradicional adquiridos em suas terras de origem, utilizando um sistema agrícola predatório, além de não conhecer as potencialidades de produção do bioma amazônico. O processo de cultivo 
inadequado para a região e a falta de apoio e incentivos do governo federal em relação aos novos colonos decretaram o insucesso dos assentamentos públicos na Amazônia e os trabalhadores rurais que se instalaram nesses assentamentos foram esquecidos e ficaram abandonados em uma região desconhecida.

O governo federal, por meio do INCRA, concedeu à CODEMAT o direito de reorganizar a ocupação da Amazônia mato-grossense por meio de projetos de colonização da iniciativa privada. A CODEMAT que já vendia terras devolutas à empresários desde a década de 1950, passou também a organizar os projetos de colonização. A ferramenta utilizada foi novamente os incentivos fiscais.

No tocante aos projetos agropecuários, os resultados vêm sendo interpretados como um notável sucesso da política de incentivos: algumas áreas dos estados do Pará e Mato Grosso, antes inexploradas, revelaramse próprias às atividades agropecuárias, e os investimentos têm sido aí superiores aos do setor industrial [...] De fato, desde 1970 já era evidente que a agropecuária estava se constituindo num setor econômico em processo de formação e consolidação, graças às condições econômicas e políticas sob as quais se desenvolvia. A aliança entre a empresa privada e o Estado, sob a égide do grande capital, era uma operação econômica e política que garantia a implantação dos projetos, a formação da burguesia agropecuária e o surgimento de uma "nova" burguesia na região amazônica. No que tange ao setor privado, a evolução do desenvolvimento regional em função de estímulos e incentivos fiscais, demonstra o aceite da concepção do sistema [...]. O advento dos incentivos fiscais para a Amazônia resultou no binômio "Governo-Iniciativa Privada"... Os incentivos fiscais são instrumentos de Política Econômica que se constituem na renúncia total ou parcial do governo, aos impostos devidos em favor da iniciativa privada objetivando o aceleramento do desenvolvimento espacial e setorial. Sendo imposto devido, a decisão de aumentar ou reduzir esta renúncia é ato e ação inconteste do governo. Mas o que ocorre na prática é a acumulação de capital no setor privado. $\mathrm{Na}$ aliança entre o Estado e a empresa privada, o que tem ocorrido é a crescente expansão do setor privado. A rigor o que ocorre é a formação e a expansão do capital privado, sob a proteção econômica e política do Estado. Mais que isso, o Estado tem sido a instância político-econômica por meio da qual uma parte do produto do trabalho coletivo (do proletariado urbano e rural) é transferido para o setor privado engajado na produção agropecuária. A vida utilizada preferencialmente para que o governo exerça influência sobre a formação de capital é a concessão de estímulos e incentivos de ordem fiscal e creditícia (IANNI, 1981, p. 227-228).

Quando o governo intensificou as vendas de terras devolutas, a política de expansão foi concretizada no Norte do Mato Grosso. Foram abertos processos de licitação onde empresas particulares adquiriram grandes porções de terras para implementar seus projetos de colonização privado. Assim foi aberta a Amazônia para a colonização denominada pelo governo de ordenada. 
Mesmo com a colonização ordenada, a política de ocupação da Amazônia continuou sendo executada da mesma forma, com imigrantes que mantinham suas práticas agrícolas predatórias e que não tinham qualquer conhecimento da região. O que realmente importava para o governo era uma nova organização do movimento migratório, formando a ocupação relativa. Os empresários colonizadores, novos proprietários das terras devolutas, faziam a seleção de acordo com as suas convicções.

Os promotores do processo de colonização, dividiam suas terras em pequenos lotes e comercializavam com os novos colonos se esses estivessem dispostos a se enquadrarem no projeto de desenvolvimento local elaborado pelos colonizadores que estavam articulados com a ditadura militar.

Na verdade, não há uma interação entre controle autoritário e racionalidade. O primeiro, contando com instrumentos de poder de caráter transitório, específico, discriminatório e acomodativo de interesse, que são os Atos Institucionais, os decretos-leis, além dos Atos Complementares; quanto a racionalidade, esta revela-se no discurso do governo através de uma retórica modernizadora, em nome do desenvolvimento econômico. Nesses contextos políticos em que se define o autoritarismo, gera-se um quadro de incerteza e um clima de medo, difusos por toda a sociedade, porque ninguém sabe ao certo de quem vem e de onde vêm as resoluções que afetam decisivamente a vida das pessoas, parecendo mais que estão submetidas a forças ocultas. [...] E foi em nome do desenvolvimento econômico e do bem-estar social que o governo autoritário justificou e estimulou a colonização particular na Amazônia sob a força dos decretosleis. O esvaziamento das tensões sociais no Sul e o aproveitamento das riquezas da Amazônia em prol do migrante, contribuindo, desta forma, para o engrandecimento da Pátria, assinalaram o conteúdo principal do discurso governamental. Os empresários e os grandes proprietários, dentro da ficção da legalidade tiveram respaldo para avançar sobre os direitos dos trabalhadores em geral (GUIMARÃES NETO, 2002, p. 55-56).

A política de ocupação foi implantada por meio do decreto federal no 59428 que exibiu em seu conteúdo, a afirmação de que o promotor da colonização dirigida, teria que ter comprovada a sua vocação para o exercício, e dessa forma, apresentou a colonização privada como um processo ordenado e seletivo, a qual tinha a segurança buscada pelos migrantes, pois seria capaz de conduzi-los à emancipação econômica.

A colonização dirigida, como parte de um referencial mais amplo, a política agrária, compreende a ocupação efetiva de áreas territoriais até então incultas e despovoadas, com o objetivo de incorporá-las produtivamente ao restante do país, ou ainda, como forma de garantir os limites de suas fronteiras. Implica na existência de terras despovoadas 
ou com reduzida população, de pessoas dispostas a migrar e, ainda, de recursos financeiros indispensáveis à realização de obras de infra-estrutura básicas à instalação dos colonos [...]. A colonização diferiria do simples povoamento por ser um processo que poderia conduzir o colono, através de um trabalho orientado, à sua independência financeira. Seria, portanto, uma ação planejada com a finalidade de povoar a terra e transformá-la em área cultivável (JATENE, 1983, p. 20).

A expansão da fronteira agropecuária e a ocupação dos vazios demográficos são afirmações contraditórias, pois na região em que foram leiloados 2 milhões de hectares, onde atualmente se encontra o município de Alta Floresta, havia grupos de posseiros que se fixaram na região após o fim do ciclo da borracha amazônica e também camponeses que chegaram à região em busca de terras e estavam há décadas instalados e realizando atividades agrícolas de subsistência.

Além de posseiros e camponeses, a serra do Cachimbo era ocupada por silvícolas.

[...] quando um avião sobrevoou suas aldeias, em 1956 o inglês Richard Manson, descendo o rio Iriri, na Serra do Cachimbo, tentou contato com os índios, mas foi morto a flechadas e borsunadas. Em 1968 os levantamentos aéreos realizados na região haviam confirmado a existência de oito aldeias de Kran-Acarôres numa área aproximadamente de $300 \mathrm{~km}$ de extensão. Calculava-se a existência de mais ou menos 1.500 índios ou até muito mais, pois cada aldeia devia agrupar pelo menos de 200 a 300 indígenas (PRETI, 1994, p. 15).

Os componentes do 9ํㅡㄹ, ao abrir caminho para a implementação da BR163, fizeram os primeiros contatos com os índios. Junto com os soldados estavam funcionários da colonizadora. Posteriormente vieram colonos, garimpeiros, todos ocupando o mesmo espaço. Problema que afetou diretamente os indígenas, que nômades, alternam de tempos em tempos o seu espaço de vivência.

Os índios acabaram por recuar, adentrando cada vez mais para o Norte. Mas a velocidade do avanço do homem branco na mesma direção era maior. A imposição do homem branco, inclusive com o uso de armas, acabou por fazer os silvícolas sucumbirem e derrotados, desestabilizados, segregados e destribalizados, os Kran-Acarôre se instalaram nas beiras das estradas mendigando, pedindo alimentos e prostituindo suas mulheres. A colonizadora INDECO sempre afirmou que não existiam índios na região de Alta Floresta, porém o processo de licitação das terras que foi realizado, teve as negociações da condições tratadas à revelia dos indígenas que habitavam a região.

Para a instalação da INDECO na região, houve alguns conflitos negados por Ariosto da Riva sempre quando questionado. A existência de índio nas terras 
onde hoje está Alta Floresta é certa devido a evidências até hoje encontradas, como ferramentas e instrumentos como peças que auxiliavam na alimentação e na caça indígena. Ainda há um ponto de turismo denominado Pedra do Índio, onde se encontram vestígios da existência dos silvícolas.

Quanto às populações indígenas que ocupavam essas terras em licitação, não tiveram nenhum poder de participação nessas decisões. A esse respeito, referindo-se aos indígenas que se encontravam nas terras da INDECO, um funcionário dessa colonizadora foi categórico: "Nós aqui domamos os índios e fizemos a limpeza” (GUIMARÃES NETO, 1986, p. 83).

Antes da licitação, além dos índios, os posseiros estavam nos arredores da área. A não implementação do Projeto Humboldt fez com que famílias se aproximassem das terras devolutas. Expedições organizadas pela INDECO com objetivo de conhecer as terras ocorriam com frequência mesmo antes do processo de licitação.

Houve tentativas de invasão e o governo militar providenciou algumas medidas para impedir a invasão. Promoveu uma barreira instalando o $16^{\circ} \mathrm{BEC}$ em Colíder (ponto de intersecção entre a BR-163 e a MT-208) que tinha por objetivo cercear o direito de ir e vir de possíveis posseiros. Mas estes não se intimidaram e permaneceram lutando pela terra na região.

Para evitar conflitos, frente as resistências dos posseiros, o governo militar criou um projeto de assentamento na região para atender as famílias de posseiros por meio do sistema cooperativista e afastá-los de onde seria construído o município de Alta Floresta. Os dois principais PAC deram origem aos municípios de Terra Nova do Norte e Guarantã do Norte.

Com as possíveis tensões controladas, o reconhecimento das terras continuava. Quando era feito por avião, Ariosto da Riva afirmou ao veículo de comunicação Folha de Londrina que:

Para vir de avião até esta área, era fazer o sobrevoo e voltar, pois não havia gasolina o suficiente. Então eu comecei a fazer o sobrevoo via Barra do Garça. Pousava na Suiá ${ }^{2}$ e descia na estrada, reabastecia com gasolina que levava no próprio avião (FOLHA DE LONDRINA, 1986, p. 3).

Algumas outras expedições foram feitas de barco. Ariosto continua a contar os seus feitos como se fora um bandeirante.

No barco além dos homens, alimentação, remédio, gerador de força era levado o combustível. E foi na margem do Teles Pires [rio que corta Alta Floresta] que se construiu no muque uma pista de pouso. Mas para

2 Para saber mais sobre a associação de Ariosto da Riva com a família Ometto no empreendimento Agropecuária Suiá-Missú S.A., licalizada no Norte de Mato Grosso, ver Tafner e Silva (2014). 
chegar até a pista, outra aventura foi necessário enfrentar a travessia da cachoeira Sete Quedas, foi preciso abrir uma picada e transportar por seis quilômetros, o barco, motores e alimentos. Levamos quarenta dias. Nessa pista fizemos análise do solo. Plantamos dendê, café, cacau. Começamos a fazer algumas experiências agrícolas (FOLHA DE LONDRINA, 1986, p. 3-4).

O solo era a maior propaganda que a INDECO poderia fazer para atrair os novos colonos. Para um empreendimento agrícola era primordial que a qualidade do solo fosse comprovada e para isso, a colonizadora buscou algumas organizações para avaliar as condições ideais para iniciar as plantações.

O colonizador foi procurar respaldo na tecnologia moderna para provar que o projeto de colonização se localizava em uma "mancha de terra fértill". Assim, de acordo com o seu depoimento, tratou imediatamente de realizar vários testes com amostras de terras encontrando cobertura para essas pesquisas no Instituto Agronômico de Campinas e junto a professores do Rio de Janeiro e Piracicaba. Além disso, contou também com o apoio do Projeto RADAM - Projeto Radar da Amazônia - que rastreava a região amazônica, indicando suas potencialidades agrícolas, apontando, inclusive, as áreas de castanhais nativos, dentre as quais Alta Floresta era uma delas. O resultado não poderia ser outro. $\mathrm{O}$ projeto de colonização de Ariosto da Riva obtinha, através da pesquisa científica, uma legitimidade que o autorizava a afirmar categoricamente: "Estamos em uma região privilegiada da Amazônia!” (GUIMARÃES NETO, 1986, p. 99).

Enquanto as pesquisas eram realizadas o governo do estado do Mato Grosso, por meio da CODEMAT, colocou as terras a venda por meio do edital no 03/73 de 25 de março de 1973. Eram os 2 milhões de hectares que seriam destinados a construção do Projeto Humboldt. Oficialmente, a área passou a pertencer a colonizadora INDECO. O processo de colonização privada de Alta Floresta iniciava-se sob o comando de Ariosto da Riva e a tutela do governador José Fragelli.

A primeira obra de infraestrutura foi a estrada MT-208 que ia do quilômetro 643 da BR-163 até onde seria a sede do município de Alta Floresta. A INDECO financiou esta abertura durante dois anos (1974-1976), construindo pontes e uma balsa para atravessar o rio Teles Pires.

Os funcionários chegaram a trabalhar 24 horas na abertura da estrada. Eram noventa funcionários divididos em dois turnos (ROSA, 1999). A INDECO queria começar a implementar o seu projeto o mais rápido possível.

Chegaram onde se instalaria a sede do município em 19 de maio de 1976. É nessa data que é comemorado o aniversário de Alta Floresta. Quando alcançaram 
o local desejado, instalaram um acampamento para pouso e recebimento e fornecimento de alimentos. Os primeiros visitantes e compradores foram recebidos nesse acampamento.

As obras de infraestrutura começaram a ser construídas ao mesmo tempo, impressionando quem fosse para Alta Floresta.

Para colonizar, principalmente com o pequeno e com o médio você tem sucesso se tiver uma terra muito boa, e que dê uma boa resposta. Agora independente da qualidade da terra, que é vital, você precisa de infraestrutura para poder dar apoio para o pessoal que vem para cá. Então tendo a terra boa, nós procuramos desde o início dar esse apoio. Fizemos logo na cidade hospital, colégio, escola, armazém, procurando dotar a região de certa infra-estrutura para inspirar confiança no colono que aqui chegasse (FOLHA DA FLORESTA, apud RIVA, 1989, p. 2).

Mas a INDECO não se limitou a esperar os visitantes na sede do município. Conforme as construções de infraestrutura foram avançando, as demarcações dos lotes rurais e urbanos foram sendo executadas, assim como a abertura das estradas vicinais dentro do município. No Sul do país, mais precisamente no Norte do Paraná, foram sendo instalados escritórios para vender as terras do Norte de Mato Grosso.

A especulação espalhou-se pela região. Caravanas eram articuladas pelos corretores para visitarem as novas terras que foram elevadas à salvação econômica para quem não tinha alcançado a independência financeira.

Torne-se um rico agricultor em Alta Floresta. Esse suplemento foi idealizado especialmente para aquelas pessoas, que, com vontade de progredir e mesmo sendo trabalhadoras, não tem conseguido campo ou chance para desenvolver-se e assim propiciar melhores condições de vida para seus familiares. O Norte de Mato Grosso com suas terras férteis, isentas de geadas ou inundações, temperatura média anual de 24 e 26 graus, regime de chuva em torno de mil milímetros anuais e bem distribuídas é uma das raríssimas oportunidades que o Brasil de hoje está lhe oferecendo. Alta Floresta é mais do que isso, é uma certeza de êxito, sobram terras e falta mão-de-obra para tudo (INDECO, 1980, p. 1).

A propaganda não se restringia somente às cidades que tinham um escritório da INDECO. Corretores em outras cidades apresentavam as novas terras nos municípios que não tinham ponto específico de vendas. Nessas cidades eram feitas reuniões na residência de alguns moradores, que chamavam os amigos para participarem, e durante as reuniões eram exibidas fotos do projeto da INDECO.

A imagem convencia, persuadia, e quem não estava vivendo em boas condições econômicas, acabava por visitar o projeto. A própria INDECO 
organizava as caravanas. Chegando na sede de Alta Floresta as terras eram oferecidas. Quem adquiria um lote não pagava a viagem, quem não comprasse nada teria que pagar as despesas. Quando retornavam de uma viagem longa, como era o caso de ir do Norte do Paraná para Alta Floresta, todos contavam aos amigos o que haviam visto. É comum no interior, a curiosidade sobre viagens de pessoas próximas, sendo normal que surjam indagações, principalmente sobre o que então era desconhecido no Sul do país.

Nessas conversas surgiam perguntas sobre a infraestrutura, qualidade de solo, clima e legalidade das posses das terras. Quando voltavam a sua cidade de origem, os colonos que não adquiriam as terras na viagem eram constantemente procurados por corretores que lhes passavam a informação de como estava o andamento do projeto.

Foi formada, no Norte do Paraná, uma longa rede de propaganda que se estendeu por toda a região. Mudar para um lugar que teria terras com solo fértil, e com o clima ideal apresentando as condições necessárias para o cultivo agrícola, significava a possibilidade concreta da emancipação econômica. Alta Floresta se apresentava como o lugar ideal.

Tudo era muito comum. Imagens das aberturas e da manutenção de estradas, construções da cidade, o crescimento das primeiras lavouras e as estatísticas que Alta Floresta apresentava.

No segundo ano de existência Alta Floresta já possui 12 milhões de pés de café plantados, 3,5 milhões de pés de cacau, sendo o único polo cacaueiro do Estado. Sobre a SAÚDE: temos 3 médicos residentes, 48 leitos, sala de operações, Raio X, Encubadeira - 800m². EDUCAÇÂO - da $1^{\mathrm{a}}$ a $8^{\mathrm{a}}$ série - com uma escola na zona urbana de $1.500 \mathrm{~m}^{2}$, e escolas rurais num total de $2.048 \mathrm{~m}^{2}$ distribuídas no projeto a $4 \mathrm{Km}$ de distância de cada lote rural ocupado. ESTRADAS - construção e conservação do Principal e Vicinais - 736Km. As terras do projeto de colonização em sua totalidade são originárias do governo do Estado. A INDECO S/A está apta a outorgar escrituras definitivas dos lotes quitados. O projeto conta ainda com o Banco do Brasil, Banco Financial e CEPLAC - Comissão Executiva do Plano da Lavoura Cacaueira (INDECO, 1978, p. 4).

Muitos compravam as terras sem ir conhecer e ver o que estavam adquirindo. Apenas números e imagens já bastavam para alguns se tornarem novos colonos de Alta Floresta.

Os pioneiros estavam, após a instalação e a primeira colheita, embriagados com o gosto da prosperidade e de terem vencido as dificuldades iniciais do projeto. Já não lembravam mais de suas renúncias e esse esquecimento das dificuldades que foi substituído pelo prazer de vitória dava sustentação à existência do 
projeto. Esse paradoxo se tornou condição para a realização de um processo de colonização privada na Amazônia.

O crescimento de Alta Floresta foi rápido. Um ano após o início da implementação do projeto, a área foi elevada a distrito de Aripuanã. Em 18 de setembro de 1979, menos de três anos após o início das obras, foi elevado à categoria de município pelo decreto-lei no 4.157. Alta Floresta ainda estava em fase de estruturação e até 31 de janeiro de 1981 a INDECO respondeu pelos problemas municipais. Na data mencionada, Wanderlei Alves Pereira tomou posse como o primeiro prefeito de Alta Floresta.

O prefeito administrou a cidade em parceria com a INDECO. O lema de seu mandato foi: nada resiste ao trabalho, frase repetida por Ariosto da Riva diversas vezes ao longo do processo de colonização. O poder público municipal atuou em parceria com a INDECO até o ano 2.000, quando Vicente da Riva, filho de Ariosto da Riva, não conseguiu a reeleição.

Nesse período a imagem de Alta Floresta continuava sendo vendida como exemplo de um resultado positivo da iniciativa privada no processo de colonização.

Em apenas dez anos, Alta Floresta já era um sucesso. Os números da sua empreitada eram impressionantes. Sem um centavo do governo, ele distribuiu terra para mais de 150 mil pessoas. Sulistas, principalmente paranaenses, chagavam as levas com seus cabelos loiros e seus olhos azuis. Eles contrastavam com uma minoria de nordestinos, todos fugindo da seca. Como a maioria dos migrantes tinha vocação agrícola, cerca de 70\% da população de Alta Floresta acabou se assentando no campo. Assim, durante quase dez anos, foram colhidas safras recordes, com consciência ecológica presente no cultivo de espécies nativas como a castanha, o guaraná e o cacau (REVISTA TERRA, 1999, p. 47).

20 anos após a emancipação de Alta Floresta, era assim vendida a sua imagem. Com informações que não correspondem com a verdade, a matéria faz uma propaganda do irreal, levantando suspeitas de que a matéria seja encomendada. Afirmar que não houve um centavo do governo é surreal, pois foi o poder público que construiu as estradas dentro do município. Muitos colonos foram financiados pelo Banco do Brasil. Funcionários do banco viajavam com helicópteros da FAB para Alta Floresta nos fins de semana para receber os colonos, avaliá-los e voltavam no começo da semana para Cuiabá para aprovarem os financiamentos. Além dessa operacionalização, lembremos que as terras onde hoje está localizada a cidade de Alta Floresta foram adquiridas por meio do governo estadual por meio de uma licitação que não envolveu empenhos monetários, apenas apresentação de projetos. Outra inverdade é a distribuição de terras para 150 mil pessoas. As terras 
não foram distribuídas, mas sim vendidas e não se atingiu o número de 150 mil pessoas. De acordo com o censo de 2.000 e 2.010, Alta Floresta tinha a população, nos respectivos anos, de 46.982 e 49.164. A INDECO continua vendendo lotes em Alta Floresta. Ainda há a afirmação de contraste entre sulistas e nordestinos, que colocando os primeiros em uma situação de superioridade apresenta o preconceito da matéria. Por fim a afirmação de consciência ecológica na produção agrícola apenas por produzirem espécies nativas não garante a sustentabilidade, além do que a maioria dos produtores plantavam café, como foi citado em um suplemento da INDECO e já no de 1999, a pecuária já apresentava a maior produtividade do município. Produzir espécies nativas não faz com que os produtores em si, adquira a consciência ecológica.

Algumas questões abordadas nessa matéria, como a ausência de incentivos fiscais e dinheiro público e a afirmação de concessão de terras, é que abriam espaços para diversas interpretações para as suas ações. Haja visto na execução de projeto, onde quem comprava as terras era protegido e ovacionado, e quem apenas visitasse Alta Floresta voltava tendo que pagar as despesas.

E essa condição era uma diferença básica para o que ele afirmou ser um sucesso do seu projeto de colonização. A principal diferença entre colonização privada e pública é a seleção de colonos. A primeira, escolhe as pessoas que têm condições de comprar uma porção de terra, e a segunda é destinada para aqueles que justamente não têm como adquiri-la.

\section{A CHEGADA DO GARIMPO EM ALTA FLORESTA}

O preço do ouro aumentou significativamente. Em 1978, a onça ${ }^{3}$ (oz) valia US $\$ 403,98$ e já no ano de 1980, a mesma medida era comercializada por US\$892,83 (MIRANDA, 1997). O rápido aumento do preço do ouro, que já era alto, chamou a atenção do poder público que passou a incentivar e investir em pesquisas, buscando aumentar a extração do ouro na Amazônia. O ouro no Norte mato-grossense, foi descoberto no rio Juruena em 1978. A jazida era distante da sede de Alta Floresta, mas a busca pelo ouro atraiu uma grande quantidade de garimpeiros que necessitavam, conforme ia aumentando o contingente, de maior espaço físico para trabalharem e se alojarem. A quantidade de colonos que chagava ao município também aumentava e Alta Floresta também ia se expandindo. O conflito de interesses entre agricultores e garimpeiros tornou-se inevitável. A ideologia do colono estava em perigo e Ariosto da Riva, monopolizador do pensamento da cidade, condenou o garimpo.

Unidade de medida de ouro equivalente a 31,1034786 gramas (MIRANDA, 1997). 
[...] chegou a haver oito, dez mil garimpeiros que quiseram dominar a cidade, implantar bordel, cabaré, no meio das famílias. O pessoal queria ir embora. Queria todo momento voltar [...] o paranaense que veio pra cá eu vou falar paranaense, mas é o paranaense, o paulista, o gaúcho -, é todo este povo que passou pela escola agrícola do Paraná, veio pra cá pensando no amanhã. Aqui todo mundo só pensa em trabalho, trabalho e trabalho (ARIOSTO DA RIVA, apud REVISTA CONTATO, 1986, p. 10).

Os garimpeiros, que não eram sulistas, foram condenados por Ariosto da Riva. Eles eram os invasores de sonhos e traziam para a sociedade valores antagônicos aos da família, como a violência e a promiscuidade. Quando os garimpeiros, atraídos pela notícia de que havia ouro no entorno de Alta Floresta, estes chegaram aos milhares e o desprezo, o preconceito e a violência contra os garimpeiros. Por ter uma formação/identidade cultural diferente do colono, o garimpeiro aparece como uma ameaça à propriedade privada e à família.

[...] O agricultor preza a terra, a família, e quer erguer uma igreja a cada esquina. O garimpeiro despreza a terra - dela só quer explorar o lucro imediato do ouro -, anda desgarrado da família e prefere um bordel a cada esquina (O ESTADO DE SÃO PAULO, 1981, p. 18).

Conforme os garimpeiros foram chegando, Alta Floresta foi se transformando. Mestiços, negros, caboclos e mulatos, sempre identificados como "nordestinos", chegavam aos milhares. Ariosto da Riva reconhece que chegou a expulsar alguns trabalhadores, mais pobres, que se dirigiam ao município.

Eu cheguei a proibir isso. Exatamente porque do Pará vinham estes garimpeiros. Não sei se você conhece Itaituba? Itaituba tem uma casa de família, um cabaré, um vendedor de maconha e depois uma casa de família de novo. É uma degradação. Se há um lugar onde se deveria jogar uma bomba atômica, este lugar é Itaituba. É um pecado. E eles queriam fazer disto aqui uma Itaituba (RIVA apud REVISTA CONTATO, 1986, p. 11).

A colonizadora INDECO, para que não houvesse uma mudança na estratégia de ocupação da região, criou, por meio da violência, uma luta de gêneros que visava os interesses da empresa, ou seja, garantir a integridade do projeto de colonização. A INDECO controlou por mais de dois anos a entrada e saída de migrantes em Alta Floresta. A ferramenta utilizada para fazer a triagem era a balsa, de propriedade da colonizadora, que era necessária para fazer a travessia do rio Teles Pires. O primeiro direito constitucional, o de ir e vir, não funcionava em Alta Floresta para os "nordestinos". 
Construída uma identidade para os garimpeiros, esta foi relatada aos colonos, e estes últimos, assimilando o discurso e a posição da INDECO, organizaram-se para tentar expulsar os garimpeiros que chegavam à Alta Floresta. O conceito de que os garimpeiros eram um ameaça à ordem municipal, pois seus hábitos e costumes eram impróprios perante a sociedade local foi assimilado pelos colonos, que se mobilizaram.

Em setembro de 1979, os agricultores expulsaram alguns garimpeiros de Alta Floresta. Esse dia até hoje é conhecido como a "vitória dos colonos".

[...] em Alta Floresta muita gente ainda cita o dia 11 de setembro de 1979 como o dia da vitória. Nesta data os colonos, usando facões e enxadas expulsaram centenas de garimpeiros e algumas prostitutas. Apesar desta vitória o garimpo se manteve inarredável (REVISTA ISTO É, 1981, não paginado).

A reação violenta dos colonos de Alta Floresta, demonstra que, para eles, os garimpeiros eram vistos como uma praga agrícola que deveria ser combatida. Mas, ainda que "centenas" de garimpeiros tenham sido expulsos, como afirma a reportagem, a notícia da descoberta de áreas de mineração na região de Alta Floresta se espalhava por todos os garimpos do Brasil, atraindo milhares de garimpeiros. A atividade mineradora atraía os trabalhadores das colonizações públicas, comandadas pelo INCRA, que fracassaram. Foi a alternativa para alguns grupos que não foram contemplados com um "futuro melhor" por meio da colonização e buscaram esse futuro no garimpo.

A colonização de Alta Floresta, não atraiu somente os colonos selecionados pelos escritórios da INDECO no Norte do Paraná. Houve um fluxo de trabalhadores que buscavam se alocar no mercado de trabalho. Para os que não conseguiam uma colocação a saída também era o garimpo.

Os locais de garimpo se proliferavam nas proximidades das áreas agrícolas pertencentes a INDECO. Não havia estradas que levassem às áreas de garimpos. O único meio de transporte era o avião. Alguns investidores, antigos garimpeiros de outras regiões do Brasil, abriram estradas em meio a mata, construindo uma pista de pouso de aviões que traziam elevavam o ouro e os garimpeiros. Ao lado destas pistas nasciam vilas que recebiam infraestrutura como farmácias, armazéns e as cabanas dos garimpeiros.

Um desses homens que abriram uma pista de pouso em meio a mata às margens do rio Paranaíta, foi o cearense Eliézio Lopes de Carvalho, conhecido em Alta Floresta como "Cabeça". A "pista" do Cabeça, tinha 500 metros de 
extensão e 40 metros de largura. Foi a principal pista de Alta Floresta, construída em 4 dias, sendo inaugurada no dia 2 de dezembro de 1981. Na pista do Cabeça, além da infraestrutura já mencionada, havia um hospital e uma escola que comportava 30 crianças. Mas também havia os cabarés. Parte dos lucros de todos os estabelecimentos, a cobrança de pousos e decolagens e uma porcentagem da venda de ouro iam para as mãos do proprietário da pista. De 1981 a 1985, período de funcionamento das atividades mineradoras na pista do Cabeça, cerca de 10 mil garimpeiros trabalharam no local. Cabeça também sabia como aumentar a sua arrecadação, estimulando os garimpeiros a gastarem o ouro que conseguiam. Cabeça promoveu shows artísticos em sua pista; Amado Batista, Waldick lá se apresentaram. Soriano, José Augusto, e Cláudia Barroso, por ç O avião de transporte dos garimpeiros sempre estaria a disposição, custando 6 gramas de ouro cada passagem. A viagem de Alta Floresta até a pista do Cabeça durava 15 minutos (REVISTA ALTA FLORESTA 26 ANOS, 2002).

Em 1988, o Sindicato dos Garimpeiros de Mato Grosso apontou a existência de 57 pistas como a do Cabeça em Alta Floresta (MIRANDA, 1997). Esse ambiente era formado por trabalhadores vindos de todas as partes do Brasil. Muitos largaram suas famílias e estavam em busca do ouro para alcançar a independência financeira. Andavam pela Amazônia procurando o Eldorado. Eram garimpeiros que se deslocavam constantemente, e que não se submetiam as regras de controle de produção e comercialização de seus resultados e não eram atingidos por qualquer instituição externa.

Era como se fosse uma terra sem governo. Cada um tinha o direito de, pela força, ou pela inteligência vir a ditar sua própria norma [...]

As barracas de moradia eram provisórias, assim como a morada de seus donos: uma lona, alguns troncos para amarrá-la e eis a casa. A comida feita ao relento e, no meio da mata uma mesa de troncos, vasilhas espalhadas sobre ela [...] em meio a tudo, uma balança para pesar o ouro (RIBEIRO, 2001, p. 64).

O colonizador teria que criar novas maneiras de lidar com o "novo", com o "outro". Para manter os garimpeiros longe do espaço da colonização, a INDECO agiu cedendo à racionalidade dos garimpeiros. Quando o ouro foi descoberto a margem do rio Teles Pires, já dentro de terras pertencentes aos colonos,

Ariosto da Riva chamou Benedito Vieira da Silva e delegou a ele a responsabilidade de cuidar dos garimpos. Homem de confiança de Ariosto, Benedito Vieira apressou-se em construir a infraestrutura e organizar os garimpos. [...] Depois de tudo providenciado, o colonizador anunciou 
aos garimpeiros recém-chegados que abriria mão de qualquer lucro no garimpo desde que eles não se metessem em terras de colonos (RIBEIRO, 2001, p. 65-66).

Benedito Vieira montou uma "pista" assim como tantas outras que havia no município, e esta era uma espécie de filial da INDECO. As ações da colonizadora acabaram melhorando as condições de trabalho dos garimpeiros. A não taxação do ouro, ao invés de manter o garimpeiro a uma certa distância da colonização fez por acontecer exatamente o contrário, o cenário passou a ser convidativo aos garimpeiros.

Com todos esses atrativos para exercer a garimpagem, cerca de 15 mil trabalhadores, originários de Itaituba (até a década de 1970 foi conhecida como a capital do ouro) no Pará, invadiram as terras dos colonos em Alta Floresta (MIRANDA, 1997). A organização do garimpo proposta por Ariosto da Riva, que visava manter os garimpeiros longe de Alta Floresta teve que recorrer à força. A polícia que atuava na região colaborou com o colonizador.

O então deputado estadual Paulo Nogueira, na Assembléia Legislativa do Estado de Mato Grosso, relatou os maus tratos sofridos pelos garimpeiros em Alta Floresta.

Foi designada uma comissão parlamentar para averiguar os fatos. Foram para Alta Floresta cinco deputados estaduais: Osvaldo Sobrinho, Ubiratan Spinelli, Candido Borges, Estevão Torquato e Hitler Sansão. Todos representantes da situação. Foram recebidos por Ariosto da Riva, que se auto encarregou de relatar os feitos que foram prontamente acatados pelos parlamentares. Após a visita a decisão dos parlamentares foi aumentar o policiamento no município.

[...] a polícia continua a agir na região de garimpos em Alta Floresta, onde espancam os garimpeiros que estão se retirando do local e confiscam todo o ouro por eles encontrado, além de promover a queima de todos os documentos que são encontrados em posse dos garimpeiros (DIÁRIO DE CUIABÁ, 1981, p. 7).

O secretário de Segurança Pública, o coronel Paulo Santa Rita Athaíde, afirmou que a sua secretaria atenderia os interesses da colonizadora 
Figura 1 - Notícia publicada no veículo Fatos Populares

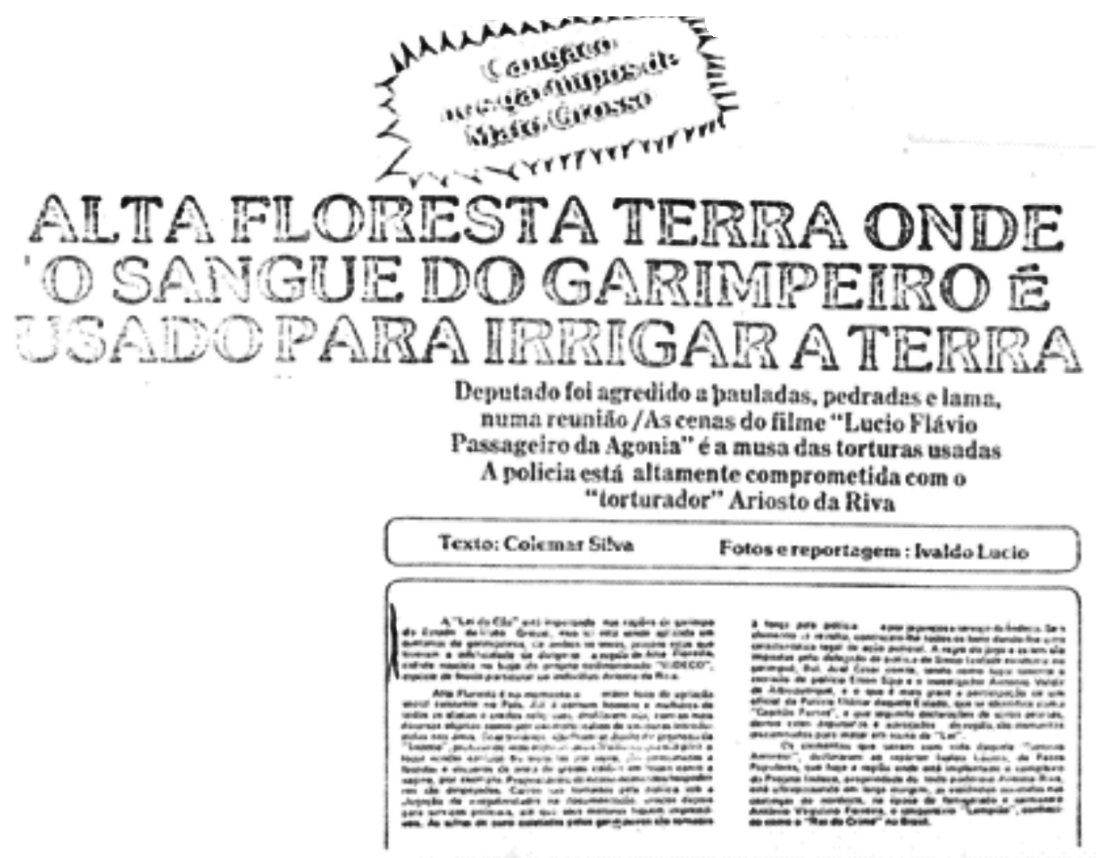

Fonte: Fatos Populares, 21 de setembro de 1981

[...] [A Secretaria] estava inteirada do problema, e que agilizaria recursos para proteger os trabalhadores. Lembrando que o governo tem o máximo interesse no progresso da região - que só se efetivará com a atuação dos agricultores - o Coronel disse que já foi nomeado outro delegado para Alta Floresta, que deve ser empossado nos próximos dias. Também o efetivo policial será ampliado visando manter a ordem naqueles distritos (DIÁRIO DE CUIABÁ, 1981, p. 7).

O espaço sem lei foi criado pela própria INDECO que tentava afastar os garimpeiros, e estes chegavam cada vez mais em maior número ao município. Os garimpeiros, homens simples e pobres, que possuíam somente sua força de trabalho, estavam buscando condições para escapar da miséria e, conforme o cenário que foi apresentado a eles, Alta Floresta era o local ideal para que isso acontecesse, pois era uma região de farta riqueza. Essa identidade única dos garimpeiros, sem apegos, contrastava com os colonos, apesar de chegarem a Alta Floreta com o mesmo objetivo: escapar da miséria. Era uma sociedade construída para os agricultores, onde os garimpeiros não tinham espaço de vivência, ao contrário, se tornaram uma ameaça ao crescimento da cidade. 
Figura 2 - Retrato da violência do garimpo de Alta Floresta

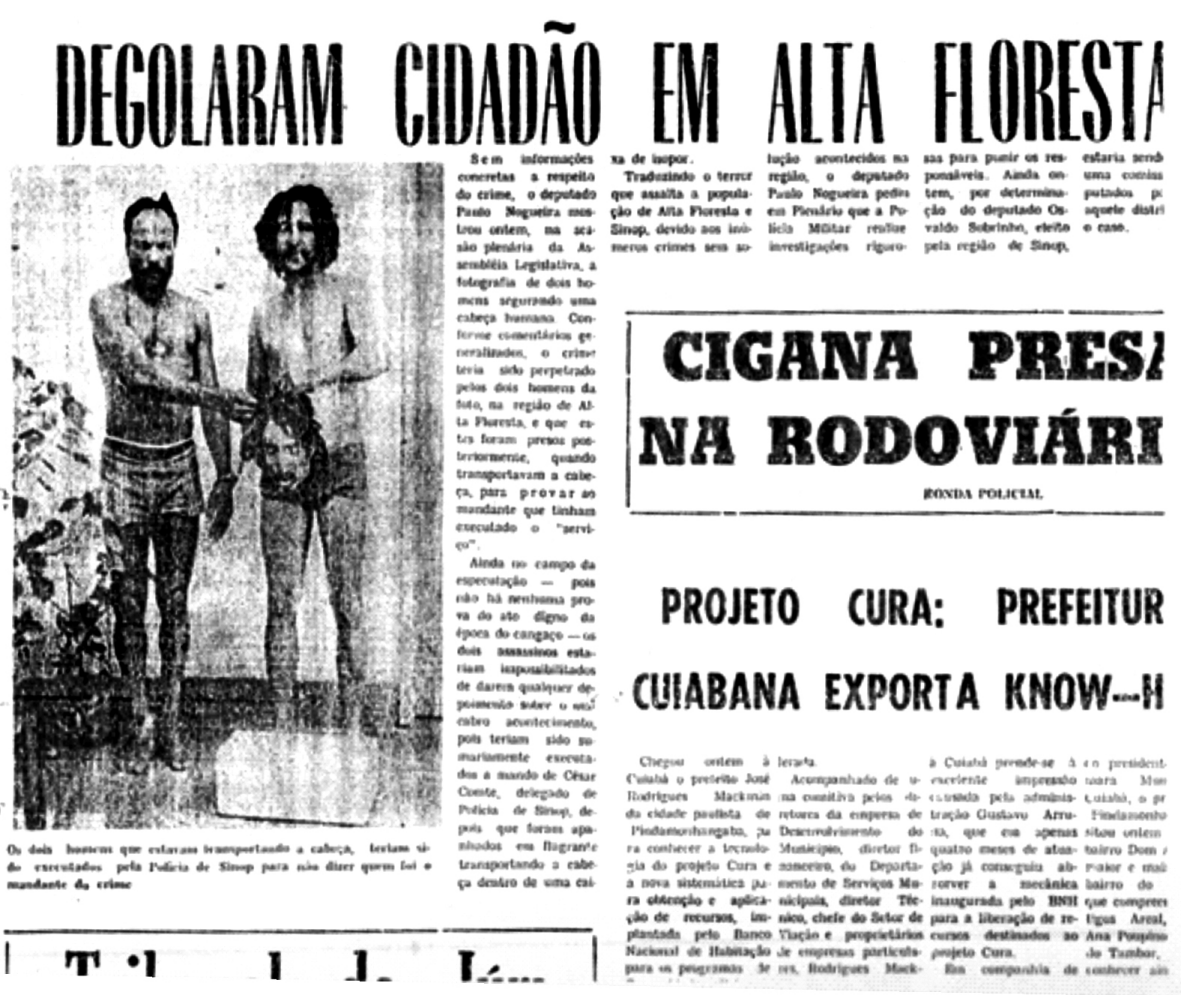

Fonte: Diário de Cuiabá, 16 de setembro de 1981

Os conflitos perduraram até 1983. Os garimpeiros resistiram à pressão feita para afastá-los dos espaços onde estavam sendo executadas as etapas do projeto de colonização da INDECO, pois enquanto os conflitos aconteciam, o garimpo desenvolvia o comércio local, gerando receita aos moradores e ao município. A aproximação de garimpeiros e colonos foi gradativa e dessa forma, o discurso do colonizador, Ariosto da Riva, já não conseguia alimentar as tensões. Houve uma sensibilização da sociedade mato-grossense, e setores representativos do Norte de Mato Grosso estavam preocupados com a imagem de tanta violência no campo.

Como "o ouro fascinava e aterrorizava, todos se corrompiam" (REVISTA ISTO É, 1981), até mesmo os agricultores se renderam ao garimpo. Alguns colonos que chegaram a Alta Floresta, logo perceberam que teriam que ter outra atividade durante o período de carência da primeira plantação. O capital que alguns agricultores traziam, não seria suficiente para se manterem nesse período. O garimpo foi a saída para que suas necessidades básicas fossem atendidas. 
Muitos arrendaram suas terras para os garimpeiros. Toda a cidade passou a estar em função do garimpo. Até mesmo as terras destinadas a agricultura passaram a ser reviradas em busca de ouro. E com a atividade garimpeira se tornando a mais produtiva da região, movimentado o comércio local a prostituição também aumentou. Em Alta Floresta instalou-se o maior prostíbulo da América Latina, chamado Saramandaia, que abrigara cerca de 600 mulheres.

[...] se arrancava um pé de café e saía "fagulhas" de ouro no meio da raiz. [No prostíbulo] tinha briga para ver quem limpava o salão no outro dia [Por quê?]. Porque a moeda era o ouro. Na cidade até as [prostitutas] se pagava com o ouro e os garimpeiros levavam as pepitas nos bolsos,e com aquela farra toda, aquela bebedeira, sempre caía alguma no chão e os garçons queriam limpar no outro dia pra procurar algum ouro. [...] os garimpeiros chegavam [no prostíbulo] tudo sujo e as [prostitutas] raspavam o corpo dos garimpeiros por que o ouro podia ficar grudado no corpo deles né [...] elas garimpavam o garimpeiro (Dalla Riva, informação verbal, 2013).

A era do garimpo em Alta floresta, iniciada em 1979, se estendeu até 1990. Pelo menos 200 empresas de compra de ouro se instalaram no município. Em 2002 havia apenas cinco empresas (REVISTA ALTA FLORESTA, 2002). Atualmente só há uma, a empresa Ourominas, que compra metal extraído basicamente do garimpo paraense de Novo Progresso.

\section{A CONJUNTURA DE ALTA FLORESTA}

Com o fim do garimpo, as atividades agrícolas tendiam a ser a principal atividade econômica de Alta Floresta, mas a produtividade da terra, cultivada aos moldes sulistas e deteriorada/contaminada pelo garimpo, foi diminuindo. Com a baixa potencialidade do solo, as áreas que seriam destinadas à agricultura, foram gradativamente substituídas por pastos e a pecuária de corte foi se estabelecendo, tornando-se atualmente a maior atividade econômica do município.

O número de cabeças de gado de corte em Alta Floresta é de 838.711, sendo 2050 proprietários. Embora haja uma grande quantidade de gado de corte, há também um alto número de criadores, o que sugere uma maior distribuição das riquezas geradas pela atividade entre os pecuaristas. O índice de Gini em Alta Floresta é de 0,34, com uma incidência de pobreza de 18,29\% (IBGE, 2013). A população de Alta Floresta é de 46.164 habitantes (IBGE, 2010). Apesar da pecuária ser o maior propulsor econômico de Alta Floresta, as externalidades negativas ocasionadas por essa atividade afetam a população florestense, sendo o desmatamento nas áreas de criação de gado bovino, a externalidade negativa de maior incidência. 
Figuras 3, 4, 5 - Evolução do desmatamento em Alta Floresta

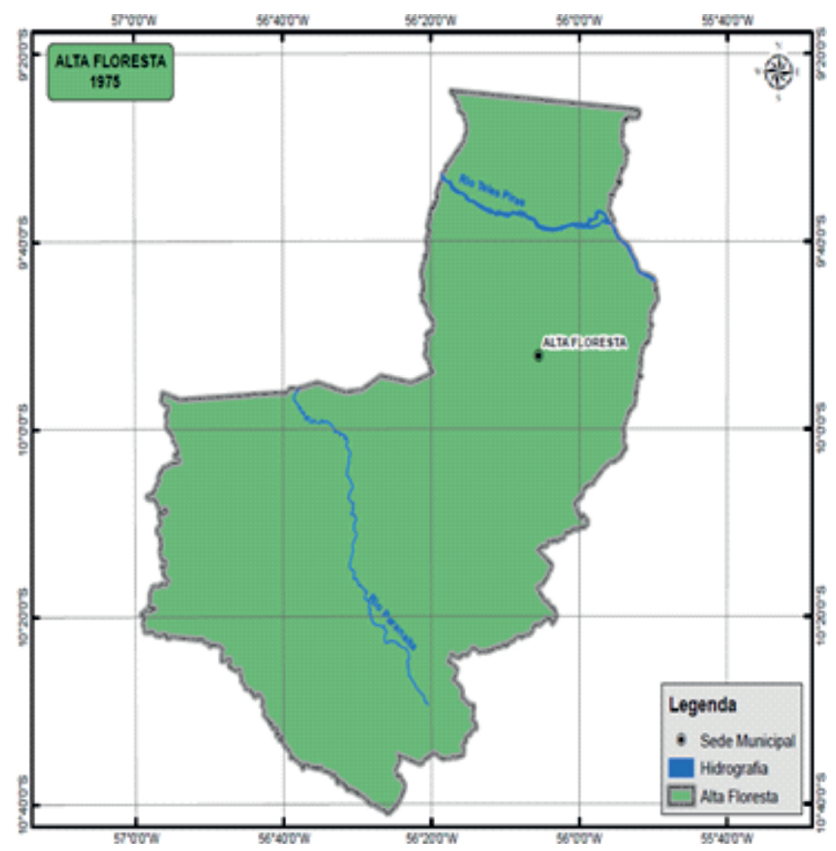

Fonte: Elaborado por Helton Luiz da Silva Campos e Armando Wilson Tafner Junior, de acordo com a base cartográfica política e administrativa do IBG; ICV (2008).

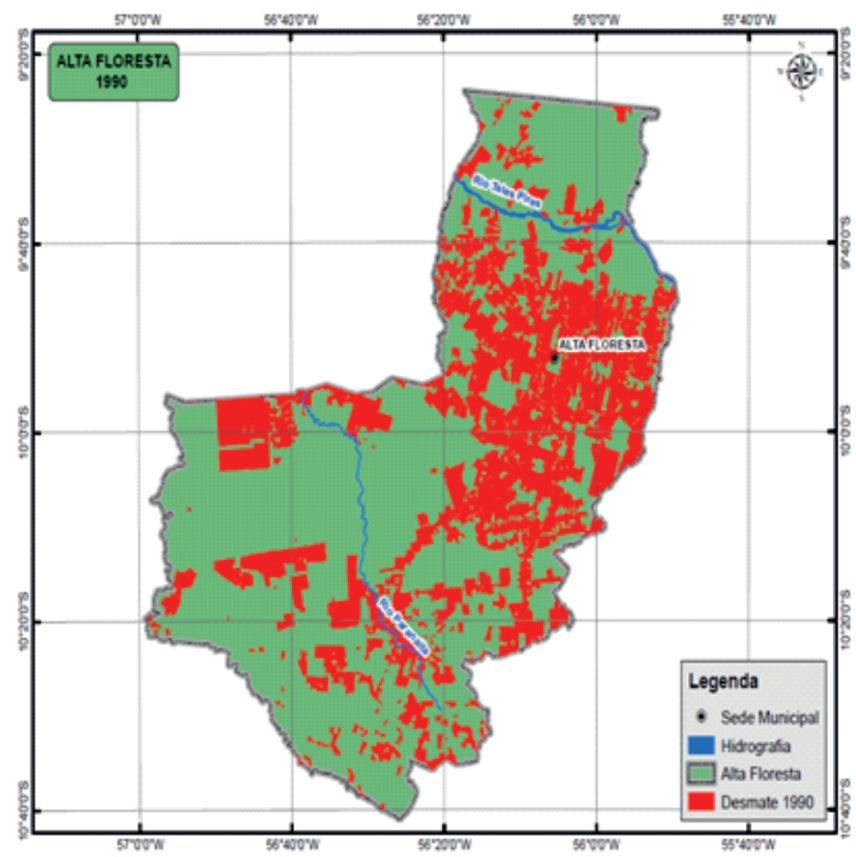

Fonte: Elaborado por Helton Luiz da Silva Campos e Armando Wilson Tafner Junior, de acordo com a base cartográfica política e administrativa do IBGE; ICV (2008). 


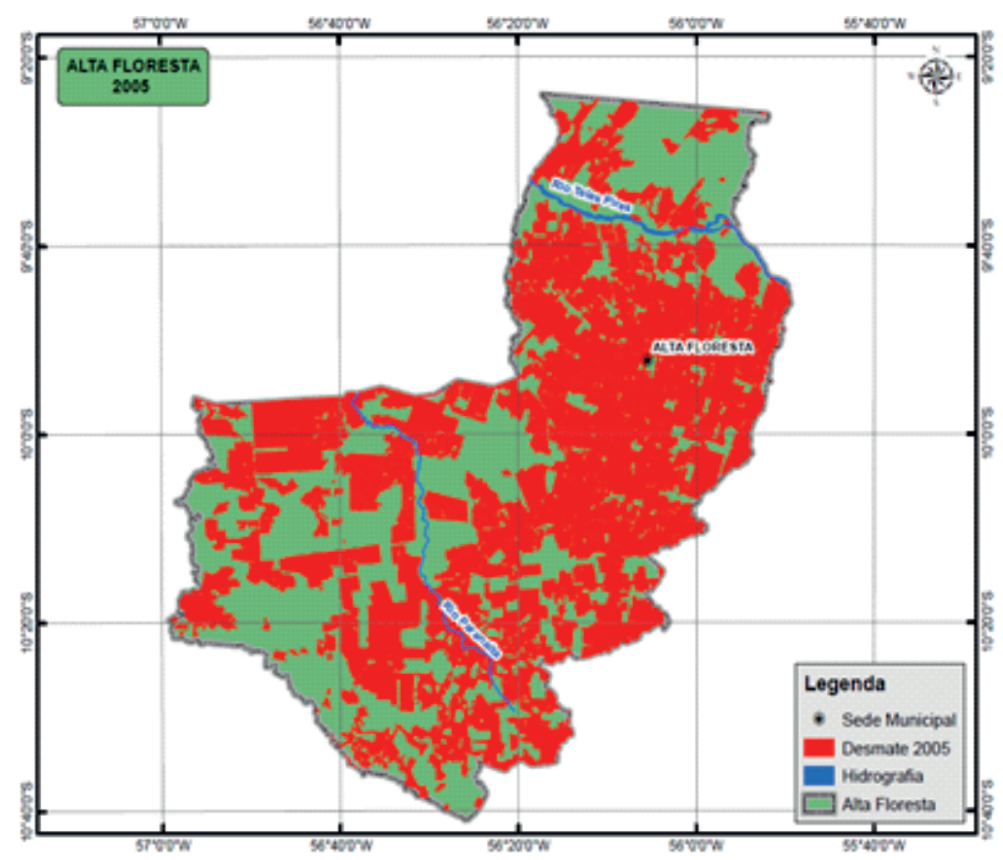

Fonte: Elaborado por Helton Luiz da Silva Campos e Armando Wilson Tafner Junior, de acordo com a base cartográfica política e administrativa do IBGE; ICV (2008)

Vê-se um aumento significativo no desmatamento de Alta Floresta ao longo do tempo, o que afeta outra atividade econômica importante do município, o ecoturismo. O município é um dos maiores polos turísticos de Mato Grosso e da Amazônia, e gradativamente, com o avanço da pecuária, vai perdendo espaço físico para desenvolver suas atividades.

\section{CONCLUSÃO}

A atividade produtiva que predomina na conjuntura econômica de Alta Floresta provoca uma transformação paisagística dentro do município. A pecuária de corte tomou conta de grande parte das terras produtivas. Essa atividade promove a concentração de terra, e o direito de propriedade acaba por inibir a chegada de novos migrantes. Nem agricultores familiar, nem garimpeiros. A atividade produtiva predominante não vai de encontro com os interesses de nenhuma atividade que outrora tentou se estabelecer em Alta Floresta. Seja por meio da INDECO, empresa de Ariosto da Riva, seja pelos garimpeiros que viriam extraia os minérios da região. 
Ariosto conseguiu implementar uma colônia, construiu aos seus moldes, em conjunto com governo militar ditatorial, influenciou os pequenos agricultores, fez uma guerra ideológica entre duas classes distintas, com isso ganhou apoio de grade parte dos migrantes que compraram suas terras. Carismático, fez com que tudo funcionasse ao seu redor desde o início da colonização até a sua falta. Muitas vezes não conseguiu, mas com mão-de-ferro sempre resistiu e nunca desistiu.

Promoveu uma busca à expulsão dos garimpeiros, e por fim, atualmente, pouco se planta em Alta Floresta, e muito se cria. A concentração fundiária está ocorrendo, e Ariosto da Riva não é mais o herói dos pequenos agricultores, pois passou a ser herói nos discursos dos pecuaristas, que estão dominando o território do pequeno agricultor que antes o exaltava. Para os garimpeiros Ariosto sempre será um déspota, agressivo e meticuloso em sua ações.

\section{REFERÊNCIAS}

ARAÚJO, R. Movimento boa nova. Belo Horizonte: O instrutor, 1999.

DALLA RIVA, C. M. Proprietário do $1^{\circ}$ cartório de Alta Floresta. Entrevista concedida ao autor em 09 de fevereiro de 2013.

FOLHA DA FLORESTA. Abril de 1989. Entrevista concedida por Ariosto da Riva ao veículo de comunicação impresso do município de Alta Floresta, 1989.

FOLHA DE LONDRINA. Fevereiro de 1986. Entrevista concedia por Ariosto da Riva ao veículo de comunicação do município de Londrina, 1986.

GUIMARÃES NETO, R. B. A Lenda do ouro verde. Cuiabá: UNICEN Publicações, 1986.

HUERTAS, D. Da fachada atlântica à imensidão Amazônica: fronteira agrícola e integração territorial. São Paulo: Annablume, 2009.

IANNI, O. A luta pela terra: história social da terra e da luta pela terra em uma área da Amazônia. Petrópolis-RJ: Vozes, 1981.

IBGE. Cidades 2013. Rio de Janeiro, 2013. . Censo 2010. Rio de Janeiro, 2010.

ICV- Instituto Centro de Vida. Iniciativas de projetos de pecuária. Alta Floresta, 2008.

INDECO - Integração, Desenvolvimento e Colonização. Alta floresta ano II. Cuiabá: [s.n.], 1980. 
. O construtor de cidades. Cuiabá, 1978.

JATENE, H. Reabertura da fronteira agrícola sob controle: a colonização particular dirigida de Alta Floresta. Campinas-SP: Unicamp, 1983.

JORNAL DIÁRIO DE CUIABÁ. Degolaram cidadão em Alta Floresta. 16 de setembro de 1981.

JORNAL DIÁRIO DE CUIABÁ. Tensão e conflito em Alta Floresta. 20 de setembro de 1981.

JORNAL O ESTADO DE SÃO PAULO. Uma história de ouro e sangue. São Paulo, 1 de abril de 1981.

JORNAL OPINIÃO. A verdadeira história de Humboldt. Rio de Janeiro, 19 set. 1975.

MIRANDA, J. A. A produção do ouro no Estado de Mato Grosso. CampinasSP: Unicamp. 1997.

PRETI, O. A colonização oficial em Mato Grosso. Cuiabá: UFMT, 1994.

REVISTA ALTA FLORESTA 26 ANOS. Cabeça, ex-rei do garimpo. Alta Floresta, 2002.

REVISTA CONTATO. Ariosto da Riva: O Imperador do Nortão. Cuiabá, maio de 1986.

REVISTA ISTO É. A última aventura. São Paulo, 24 de abril de 1981.

REVISTA TERRA. Uma aventura na selvagem Alta Floresta. Ed. Abril. São Paulo, 1999.

RIBEIRO, J. Terra e garimpo. Cuiabá: UFMT, 2001.

ROSA, R. A Constituição da escola com um espaço de formação do colono junto aos projetos de colonização do Norte mato-grossense: Alta Floresta, 1976 a 1996. 1999. Dissertação (Mestrado em Educação) - Universidade Federal do Paraná, Curitiba, 1999. 


\section{ANEXO \\ CANGAÇO NOS GARIMPOS DE MATO GROSSO \\ ALTA FLORESTA TERRA ONDE O SANGUE DOS GARIMPEIROS É USADO PARA IRRIGAR A TERRA}

Deputado foi agredido a pauladas, pedradas e lama, numa reunião/As cenas do filme "Lucio Flávio Passageiro da Agonia" é a musa das torturas usadas. A polícia está altamente comprometida com o "torturador" Ariosto da Riva. Texto: Colemar Silva

Fotos e reportagens: Ivaldo Lúcio

A “Lei do Cão" está imperando nas regiões de garimpo do Estado de Mato Grosso, essa lei está sendo aplicada em centenas de garimpeiros de ambos os sexos, pessoas essas que tiveram a infelicidade de dirigir-se a região de Alta Floresta, cidade nascida no bojo do projeto codinominado "INDECO", espécie de feudo particular do indivíduo Ariosto da Riva.

Alta Floresta é no momento o maior foco de agitação social existente no País. Ali é comum homens e mulheres de todas as idades e credos religiosos, desfilarem nús, com os mais diversos objetos, como por exemplo, cabos de vassouras introduzidos no ânus. Garimpeiros apontam a polícia e os jagunços da "INDECO", por atraírem acompanhantes mulheres e as obrigarem a ir para um local vender carícias ou trocá-las por ouro. Eram assassinadas a facadas e disparos de arma de grosso calibre em locais como a vagina, por exemplo. Proprietários de estabelecimentos hospedeiros são despejados. Carros são tomados pela polícia sob a alegação de irregularidades na documentação, e são usados depois para serviços policiais, até que seus motores fiquem imprestáveis. As safras de ouro coletadas pelos garimpeiros, são tomadas a força pela polícia e por jagunços a serviço da "INDECO". Se o elemento se revolta, confiscam-lhe todos os seus bens, dando-lhe uma característica legal de ação policial. As regras do jogo e as leis são impostas pelo delegado de polícia de SInop (cidade existente no garimpo), Cel. José César Comte, tendo como lugar tenente o escrivão de polícia Élson Sipp e o investigador Antônio Valdir de Albuquerque, e o que é mais grave é a participação de um policial militar daquele Estado, que se identifica como "Capitão Fortes", e que segundo declarações de diversas pessoas, dentre estas deputados e advogados da região, são elementos credenciados para matar em nome da "Lei".

Os elementos que saíram com vida daquele "Inferno Amarelo" declararam ao repórter Ivaldo Lucio, de Fatos Populares, que hoje a região onde está 
implantado o escritório do Projeto INDECO, propriedade do todo poderoso Ariosto da Riva, está ultrapassando em larga margem, as violentas atividades nas caatingas do Nordeste, ma época do famigerado e carniceiro Antônio Virgolino Ferreira, o sanguinário "Lampião", conhecido como o "Rei do Crime" no Brasil.

\section{DEGOLARAM CIDADÃO EM ALTA FLORESTA}

Sem resultados concretos a respeito do crime, o deputado Paulo Nogueira mostrou ontem, na sessão plenária da Assembléia Legislativa, a fotografia de dois homens segurando uma cabeça humana. Conforme comentários generalizados, o crime teria sido perpetrado pelos dois homens da foto, na região de Alta Floresta, e que estes foram presos posteriormente, quando transportavam a cabeça, para mostrar ao mandante que tinham executado o "serviço".

Ainda no campo da especulação - pois não há nenhuma prova do ato digno da época do cangaço - os dois assassinos estariam impossibilitados de darem qualquer depoimento sobre o macabro acontecimento, pois teriam sido sumariamente executados a mando de César Comte, delegado de Polícia de Sinop, depois que foram apanhados em flagrante transportando a cabeça dentro de uma caixa de isopor.

Traduzindo o terror que assalta a população de Alta Floresta e Sinop, devido aos inúmeros crimes sem solução acontecidos na região, o deputado Paulo Nogueira pediu em Plenário, que a Polícia Militar realize investigações rigorosas para punir os responsáveis. Ainda ontem, por determinação do deputado Osvaldo Sobrinho, eleito pela região de Sinop, estaria sendo montada uma comissão de deputados para se direcionar aquele distrito e avaliar o caso. 